\title{
Definition of an On-Board Comfort Index (Rail) for the Railway Transport
}

\author{
Vincenzo Barone, Domenico Walter Edvige Mongelli, and Antonio Tassitani \\ Department of Civil Engineering, University of Calabria, Arcavacata, 87036 Rende, Italy \\ Correspondence should be addressed to Antonio Tassitani; antonio.tassitani@unical.it
}

Received 17 February 2017; Revised 12 May 2017; Accepted 20 June 2017; Published 24 July 2017

Academic Editor: Dongjoo Park

Copyright ( 2017 Vincenzo Barone et al. This is an open access article distributed under the Creative Commons Attribution License, which permits unrestricted use, distribution, and reproduction in any medium, provided the original work is properly cited.

\begin{abstract}
The use of collective transport is strongly influenced by the quality of offered service. One of the overriding factors that affect the modal shift process is the quality of transport systems. To increase the attractiveness of collective transport services and therefore reduce the use of cars, authorities in collaboration with transport companies should take steps to ensure a high level of service quality in the public transport system. The provided quality is the level of quality achieved on daily basis and measured by the customer/user point of view. This research aims to relate service quality perceived by the user to measurements of two environmental indicators, that is, vibration, in reference to which the acceleration transmitted to the body by the vehicle motion and by its vibration will be measured, and noise, in reference to which the Equivalent Sound Pressure Level_Leq $(A)$ - will be measured. Finally, a Comfort Index (CI) (rail) is specified, calibrated, and validated.
\end{abstract}

\section{Introduction}

The public transport demand can be a lever to stimulate innovation, competitiveness, and thus system growth and employment. These are considerations emerged following the Europe 2020 Document, innovation as strategic priority for growth and employment. The development of collective transport systems in order to create a sustainable and quality system can ensure the achievement of objectives set by the European Commission in the Europe 2020 project [1].

Today, the determination of collective transport systems quality is performed through two typologies of measurements, objective (delay, frequency, crowding level, etc.) and subjective (safety level, cleaning level, etc.).

The quality of service, according to the UNI EN 13816 [2], distinguishes four types of services: by the customer/user point of view, expected quality and perceived quality; by the service providers point of view, planned quality and provided quality. These aspects are placed in circular relationship according to a cyclical principle (expected service quality, planned service quality, provided service quality, perceived service quality, expected service quality, etc.).

The performance indicators are used to describe and/or measure a specific operating aspect of a shipping company or of a specific line or race. Such indicators must have some particular characteristics, which allow a simple and reliable use, being able to interpret the changes over time of transport system characteristics and the differences between various conditions.

Indicators are also useful and necessary to predict (in the process of service planning and design) and verify (in the process of service management and control) the performance of the transport system. In the first case, indicators are computed in advance through a simulation based on forecasts; in the second case, instead, they are measured or calculated in relation to the effective system operation, during the operating phase of the system itself.

The indicators used for performance measurements of a collective transport system can be traced to three features of the service:

(i) efficiency, measured as the ratio of the quantities produced and those consumed in the process;

(ii) productivity, measured as a function of the time taken to produce a certain service;

(iii) consumption and production, measured as the ratio between the amount of resources used in the production process and the amount of products. 
Some modern studies allow determining the on-board users comfort using smartphones' sensors. Lin et al. [3] propose a methodology to measure the comfort on public transport vehicles using an index called Comfort Measuring System CMS. The CMS system is comprised of three parts:

(i) measurements obtained through the detection of smartphones' sensors;

(ii) database provided by operators of the transport system;

(iii) algorithm to determine results, using measurements from smartphones and from the database.

However, the use of smartphone sensors does not guarantee the same degree of accuracy as the instrumentation used in this work.

Andaleeb et al. [4] study the bus transport services in Dhaka, Bangladesh. In this study, eight factors were identified to represent the satisfaction levels of regular bus users. Using a factor analysis and multiple regressions, five of the eight selected factors were found to have significant effects on passenger satisfaction. Passengers consider the following factors as the most important defining the quality of transport system: comfort levels, staff behavior, number of buses changed to reach destination, supervision, and waiting facilities.

Cantwell et al. [5] examine the level of stress caused by commuting into Dublin city centre. Moreover, the study determines the comfort value and the reliability of public transport services in Dublin city. An online survey, State Preference (SP) type, was subjected to users in order to collect data on movements, satisfaction levels, and commuting. These data were processed using a multinomial Logit model, which showed that utility as crowding derived increases and decreases as reliability increases.

Several studies and reviews have largely dealt with the discomfort related to traffic noise in urban areas, in particular [6-12] by relating road infrastructure characteristics and vehicular traffic to simulate the noise level. There have been several improvements in this research topic [13-15], for instance, with the introduction of dynamical models. These studies do not define an index and/or a scale to define the acoustic comfort but merely characterize the problem and define predictive calculation models.

A further study [16] investigates the influence of tunnels on comfort on high-speed trains, simulating, in a pressure chamber, the only acoustic discomfort due to the crossing of railway tunnels. The study demonstrates using a scale from 0 to 6 , as the lowest discomfort was obtained for the condition with the highest increase in sound pressure level $(+12 \mathrm{~dB}$ noise tunnel).

Studies conducted by [17-19] use various applications associated with the concept of participatory sensing phone. The use of smartphones, specifically of the sensors within them, enables innovative uses also in user behavior study.

Other studies [20] show that the use of the same acceleration sensors can be helpful in determining on-board comfort and users driving style, both in private and public transport systems. Furthermore, Festa et al. [20, 21] show that
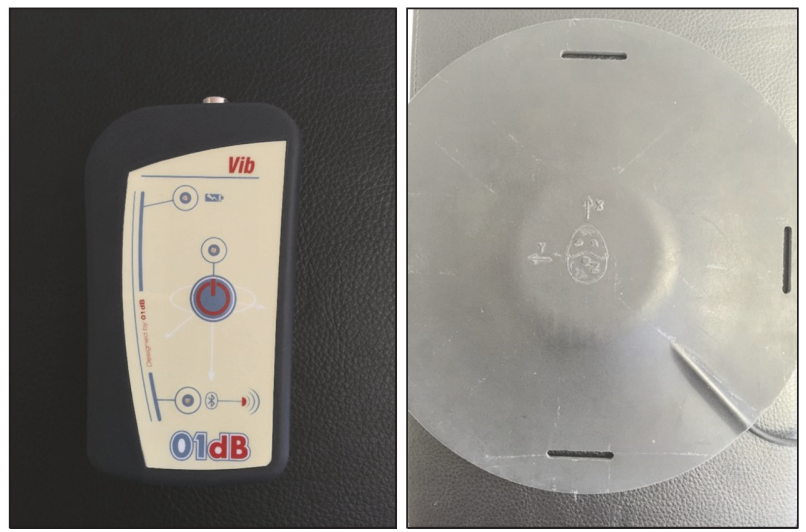

FIGURE 1: Vibration dosimeter VIB 008, $01 \mathrm{~dB}$.

the combined use of two sensors in a smartphone, namely, the microphone and the accelerometer, allows determining even road anomalies along the route, by means of a suitable calculation algorithm. The study conducted by Barone et al. [22] shows how the use of a high precision instrumentation, as a noise dosimeter and a vibration dosimeter, allows greatly simplifying the algorithm used for the identification of road anomalies.

\section{The Instrumentation}

The instrumentation used during experimentations was provided by the $01 \mathrm{~dB}$ Acoem company, through the AESSE Ambiente company which signed an agreement protocol with the University of Calabria. Instrumentation is represented by those reported in the following.

2.1. Vibration Dosimeter VIB 008. Vibration dosimeter VIB 008 is an instrument dedicated to "hand-arm" and "wholebody" vibration measurements, in accordance with the European Directive [23] and the consequent Italian implementing decrees [24]. The instrument also complies with standards $[25,26]$. The vibrometer has reduced dimensions and is ergonomic, allowing ease of use in acquisition of data, which can be stored and transferred on any PC or tablet with Windows operating system. The kit used during experimentations, shown in Figure 1, is composed by a capture, storage, and data transfer device and by an accelerometer with the relative set for the whole-body vibration measurement. The accelerometer, shown in Figure 1, must be placed on the passenger seat, respecting the axes direction indicated on the pillow.

\subsection{Noise Dosimeter WED 007. Noise dosimeter WED} 007 is an instrument dedicated to noise measurements in accordance with standards [27, 28]. The kit used during experimentations, shown in Figure 3, is composed by a capture, storage, and data transfer device and by a microphone MCE321 of class 2, with an integrated preamplifier. The microphone, shown in Figure 2, is also provided with a cable that allows placement near the user's ear. 

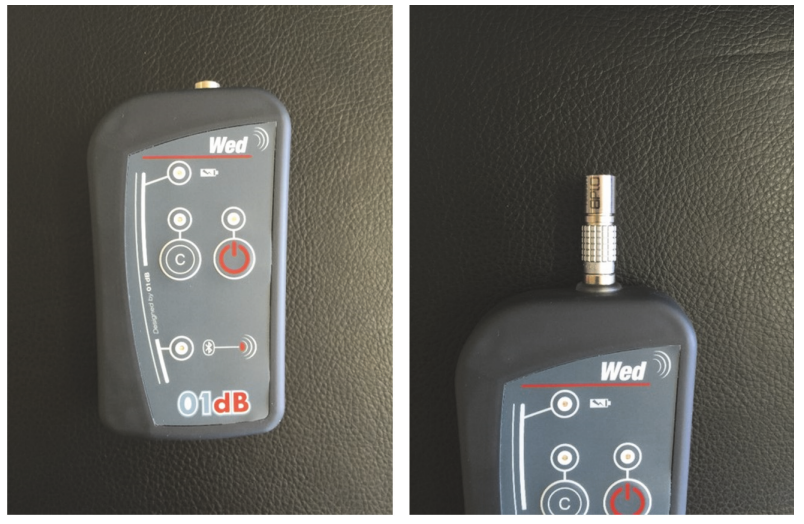

FIgURE 2: Noise dosimeter WED 007 with microphone, $01 \mathrm{~dB}$.

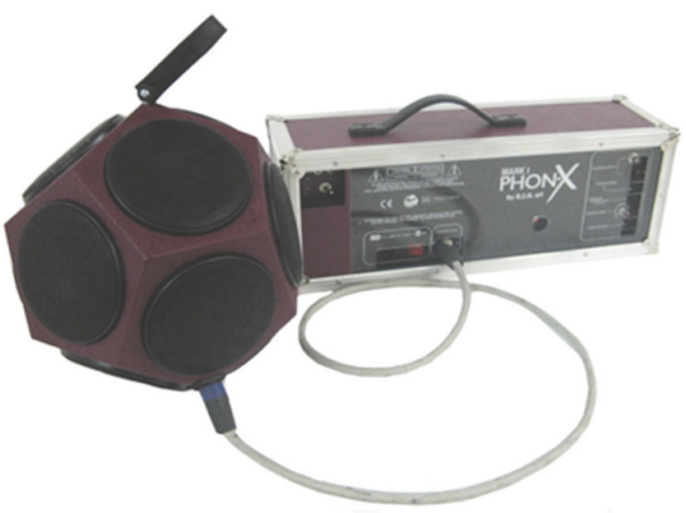

Figure 3: Dodecahedron FOUR and amplifier PHON-X Mark I.

2.3. Dodecahedron FOUR and Amplifier PHON-X Mark I. It is an omnidirectional acoustic diffuser, mainly used to measure the soundproofing power between different environments (according to the current regulations D.P.C.M. 05/12/97 and UNI 11367) and the reverberation time of environments (ISO 354). Thanks to the use of a dedicated amplifier, the FOUR, shown in Figure 3, is capable of emitting a noise level sufficient to characterize the most environments. FOUR meets the requirements of ISO 140 and ISO 3382.

\section{Preliminary Sample Survey}

Preliminarily a sample survey SP type (State Preference) was conducted on a sample of 250 users who habitually use the public transport system, with the aim to involve users in the referencing process of transport service quality, overturning the concept of customer satisfaction currently used by public service operators.

For the preliminary survey, the test signal used is that called "pink noise," to provide a constant sound level on all third octave bands, that is, a third degree octave band spectrum.

A sounds set, previously recorded inside the trains running along the reference test site, was defined and encoded according to the equivalent sound level (Leq $(A)$ ). Interviewees have listened, through Dodecahedron FOUR, to

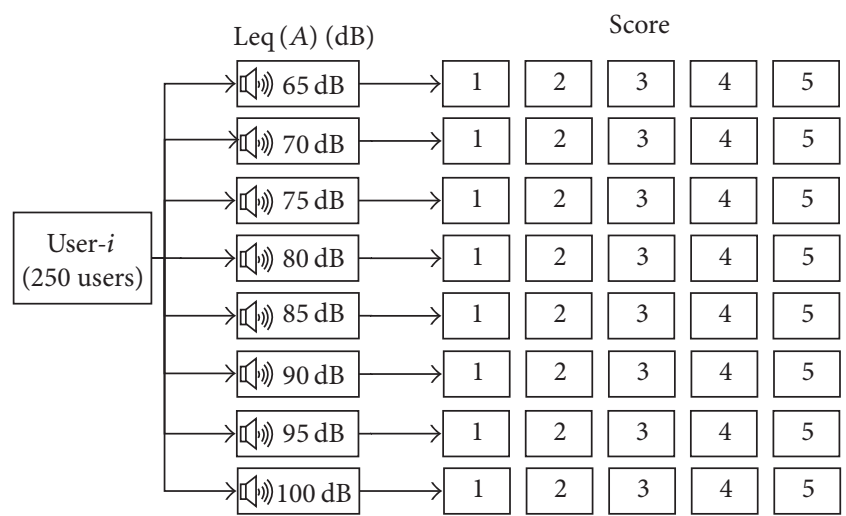

FIgure 4: Preliminary sample survey flow chart to detect the perceived noise level.

8 different recordings with predetermined equivalent sound levels (with a tolerance of $\pm 2 \mathrm{~dB}$ ):

(i) $65 \mathrm{~dB}$ : noise produced by Stadler train with engine running at the station

(ii) $70 \mathrm{~dB}$ : noise produced by FIAT train with engine running at the station;

(iii) $75 \mathrm{~dB}$ : noise produced by Stadler train during the trip on a straight section without obstacles and/or tunnel;

(iv) $80 \mathrm{~dB}$ : noise produced by Man train during the trip on a straight section without obstacles and/or tunnel;

(v) $85 \mathrm{~dB}$ : noise produced by Stadler train during the trip on a tunnel section;

(vi) $90 \mathrm{~dB}$ : noise produced by FIAT train during the trip on a section with positive slope and side obstacles;

(vii) $95 \mathrm{~dB}$ : noise produced by Man train during the trip on a tunnel section without slope;

(viii) $100 \mathrm{~dB}$ : noise produced by Man and FIAT trains during the trip on a tunnel section with positive slope.

These recordings have a term of 3 seconds and were heard by the user in random sequence. In particular, at the railway stations located along the reference test site, we asked users to match the level of perceived noise with the Dodecahedron FOUR connected to the amplifier PHON-X Mark I, through a scale from 1 (highly comfortable) to 5 (extremely uncomfortable).

The sample survey schematization is shown in the flow chart of Figure 4.

Results obtained from the preliminary sample survey on 250 users are summarized in Table 1 and Figure 5.

Similar considerations were addressed to determine the thresholds to be attributed to vibrations perceived by the users on board the vehicle. However, since it is complicated to simulate a set of vibrations with predetermined thresholds to be subjected to the collective transport users, the survey was conducted with a private vehicle (Land Rover Freelander 2) on a reference test site located on Viale Principe in Rende (CS) with the collaboration of 100 users. 
TABLE 1: Preliminary sample survey results to detect the perceived noise level.

\begin{tabular}{|c|c|c|c|c|c|c|c|c|c|c|}
\hline \multirow{3}{*}{$\operatorname{Leq}(A)[\mathrm{dB}]$} & \multicolumn{10}{|c|}{ Noise perceived } \\
\hline & \multicolumn{2}{|c|}{1} & \multicolumn{2}{|c|}{2} & \multicolumn{2}{|c|}{3} & \multicolumn{2}{|c|}{4} & \multicolumn{2}{|c|}{5} \\
\hline & Number & $\%$ & Number & $\%$ & Number & $\%$ & Number & $\%$ & Number & $\%$ \\
\hline 65 & 247 & 98.8 & 2 & 0.8 & 1 & 0.4 & 0 & 0.0 & 0 & 0.0 \\
\hline 70 & 241 & 96.4 & 6 & 2.4 & 3 & 1.2 & 0 & 0.0 & 0 & 0.0 \\
\hline 75 & 32 & 12.8 & 164 & 65.6 & 21 & 8.4 & 33 & 13.2 & 0 & 0.0 \\
\hline 80 & 7 & 2.8 & 41 & 16.4 & 135 & 54.0 & 46 & 18.4 & 21 & 8.4 \\
\hline 85 & 0 & 0.0 & 0 & 0.0 & 2 & 0.8 & 3 & 1.2 & 245 & 98.0 \\
\hline 90 & 0 & 0.0 & 0 & 0.0 & 1 & 0.4 & 3 & 1.2 & 246 & 98.4 \\
\hline 95 & 0 & 0.0 & 0 & 0.0 & 0 & 0.0 & 0 & 0.0 & 250 & 100.0 \\
\hline 100 & 0 & 0.0 & 0 & 0.0 & 0 & 0.0 & 1 & 0.4 & 249 & 99.6 \\
\hline
\end{tabular}

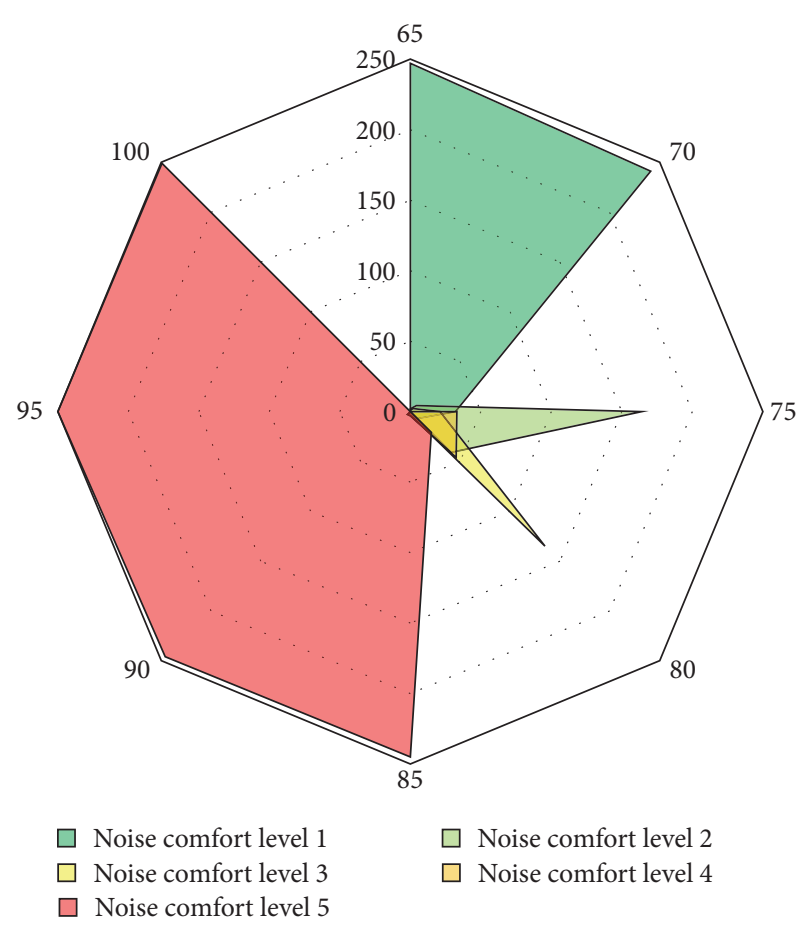

FIGURE 5: Preliminary sample survey results to detect the perceived noise level.

Starting from the study [29], in which the relationship between the traveling speed of vehicles and the acceleration $a_{v}$ (overall whole-body vibration acceleration) is demonstrated, specific speed thresholds were defined allowing obtaining certain values of acceleration. Each user was asked to give, by means of a scale from 1 (highly comfortable) to 5 (extremely uncomfortable), the level of vibrational comfort perceived on the vehicle that runs with predetermined speed (with a tolerance of $\pm 2 \mathrm{~km} / \mathrm{h}$ ):

(i) $\mathrm{Vm}=20 \mathrm{~km} / \mathrm{h}$ : determines an acceleration value $\left(a_{v}\right)$ of about $0.20 \mathrm{~m} / \mathrm{s}^{2}$;

(ii) $\mathrm{Vm}=30 \mathrm{~km} / \mathrm{h}$ : determines an acceleration value $\left(a_{v}\right)$ of about $0.35 \mathrm{~m} / \mathrm{s}^{2}$;

(iii) $\mathrm{Vm}=35 \mathrm{~km} / \mathrm{h}$ : determines an acceleration value $\left(a_{v}\right)$ of about $0.50 \mathrm{~m} / \mathrm{s}^{2}$; (iv) $\mathrm{Vm}=40 \mathrm{~km} / \mathrm{h}$ : determines an acceleration value $\left(a_{v}\right)$ of about $0.65 \mathrm{~m} / \mathrm{s}^{2}$;

(v) $\mathrm{Vm}=45 \mathrm{~km} / \mathrm{h}$ : determines an acceleration value $\left(a_{v}\right)$ of about $0.90 \mathrm{~m} / \mathrm{s}^{2}$;

(vi) $\mathrm{Vm}=50 \mathrm{~km} / \mathrm{h}$ : determines an acceleration value $\left(a_{v}\right)$ of about $1.20 \mathrm{~m} / \mathrm{s}^{2}$.

Parameters used to determine vibrational comfort on board are $a_{w}$ (frequency-weighted RMS acceleration in $\mathrm{m} / \mathrm{s}^{2}$, along the three axes $x, y$, and $z$ ) and $a_{v}$, overall whole-body vibration acceleration, determined using the following formulation:

$$
a_{v}=\left[\left(K_{x} \cdot a_{w x}\right)^{2}+\left(K_{y} \cdot a_{w y}\right)^{2}+\left(K_{z} \cdot a_{w z}\right)^{2}\right]^{0.5},
$$

where

(i) $a_{w x}, a_{w y}$, and $a_{w z}$ are the weighted RMS acceleration with respect to the orthogonal axes $x, y$, and $z$, respectively;

(ii) $K_{x}, K_{y}$, and $K_{z}$ are multiplying factors with respect to the orthogonal axes $x, y$, and $z$, respectively.

The sample survey schematization is shown in the flow chart of Figure 6.

Results obtained from the preliminary sample survey on 100 users are summarized in Table 2 and Figure 7.

\section{Sample Survey on Railway Transport}

Once thresholds for defining the Comfort Index were identified starting from preliminary sample survey results, a second survey on public transport vehicle (trains) was carried out, in order to define the level of vibration and acoustic comfort perceived by users on board the vehicle and to identify which component between noise and vibration is more significant, according to the users, in the same comfort definition.

The survey covered about 250 regular passengers of the public transport system, to which a questionnaire was administered. Users of the transport service were asked to express a unified judgment on which one of the two factors (noise and vibration) has greater effect in the definition of onboard comfort, with the aim to define the weight to assign to each variable. 
TABLE 2: Preliminary sample survey results to detect the perceived vibration level.

\begin{tabular}{|c|c|c|c|c|c|c|c|c|c|c|}
\hline \multirow{3}{*}{$a_{v}\left[\mathrm{~m} / \mathrm{s}^{2}\right]$} & \multicolumn{10}{|c|}{ Vibration comfort perceived } \\
\hline & \multicolumn{2}{|c|}{1} & \multicolumn{2}{|c|}{2} & \multicolumn{2}{|c|}{3} & \multicolumn{2}{|c|}{4} & \multicolumn{2}{|c|}{5} \\
\hline & Number & $\%$ & Number & $\%$ & Number & $\%$ & Number & $\%$ & Number & $\%$ \\
\hline 0.20 & 97 & 97.0 & 3 & 3.0 & 0 & 0.0 & 0 & 0.0 & 0 & 0.0 \\
\hline 0.35 & 13 & 13.0 & 85 & 85.0 & 2 & 2.0 & 0 & 0.0 & 0 & 0.0 \\
\hline 0.50 & 0 & 0.0 & 28 & 28.0 & 70 & 70.0 & 2 & 2.0 & 0 & 0.0 \\
\hline 0.65 & 0 & 0.0 & 26 & 26.0 & 69 & 69.0 & 5 & 5.0 & 0 & 0.0 \\
\hline 0.90 & 0 & 0.0 & 0 & 0.0 & 1 & 1.0 & 4 & 4.0 & 95 & 95.0 \\
\hline 1.20 & 0 & 0.0 & 0 & 0.0 & 0 & 0.0 & 1 & 1.0 & 99 & 99.0 \\
\hline
\end{tabular}

TABLE 3: Sample survey results on public transport vehicle to identify the weights $\alpha_{n}$ and $\alpha_{v}$.

\begin{tabular}{lccc}
\hline Vibration comfort perceived & \multicolumn{3}{c}{ Noise perceived } \\
Number & $\%$ & Number & $\%$ \\
\hline 73 & 29 & 177 & 71 \\
\hline
\end{tabular}

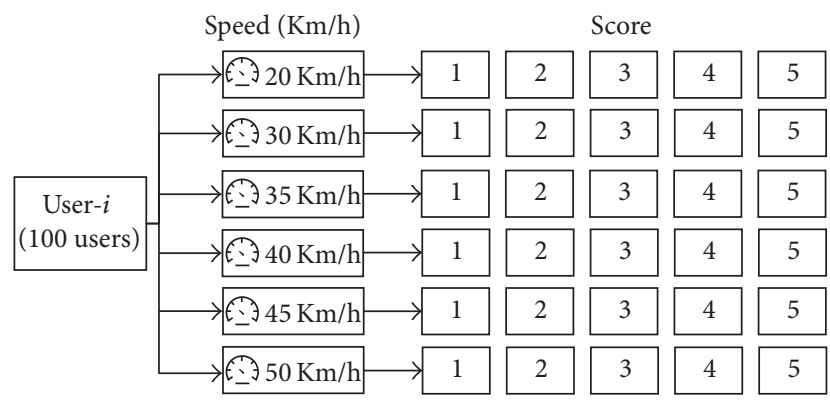

FIgURE 6: Preliminary sample survey flow chart to detect the perceived vibration level.

In addition to socioeconomic questions useful to identify the sample interviewed, the same users were asked to assign a unique value from 1 to 10 to the perceived comfort on board the vehicle. This value allowed obtaining a corresponding perceived comfort (CP) (rail) on the route.

Interviewees are regular users of the transport system mainly for home-work and home-school commuting.

Two tests were used to validate the sample survey: Retest test to measure the stability of the survey and $\alpha$-Cronbach test to measure the reliability of the survey. The $r$-Pearson value equal to 0.87 and the $\alpha$-Cronbach value equal to 0.86 were calculated and are indicative of the stability and reliability of the sample survey.

Following the elaboration of answers provided by users in the 250 survey forms, it was possible to determine the weights $\left(\alpha_{n}\right.$ and $\left.\alpha_{v}\right)$ attributable to the two variables in the comfort definition. The summary results of this survey are shown in Table 3.

Values obtained from processing the sample survey results on public transport vehicle, in particular, highlighted that perceived noise on board the vehicle affects about $70 \%$ in determining the on-board comfort, according to the users.

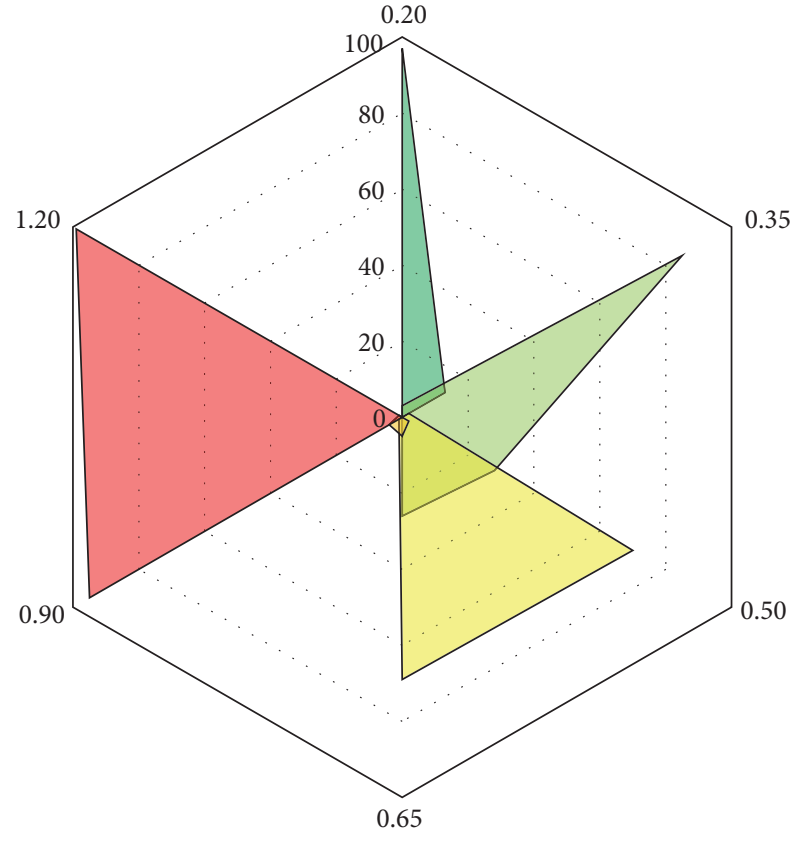

$\square$ Vibration comfort level 1
$\square$ Vibration comfort level 3
$\square \quad$ Vibration comfort level 5

FIGURE 7: Preliminary sample survey results to detect the perceived vibration level.

\section{The Comfort Index (CI) (Rail)}

In order to determine the on-board comfort in public transport systems we propose a Comfort Index (CI) (rail) useful to uniquely identify the comfort level of the considered transport system. This CI (rail) was studied starting from two variables:

(i) noise measured on board the vehicle during the trip;

(ii) vibrations measured on board the vehicle during the trip.

In defining the CI (rail) formulation, a weight was assigned to each measured variable, starting from indications emerged from the 250 survey forms submitted during the investigation on public transport. Specifically, the CI (rail) was determined for the rail transport system. 
TABLE 4: Identification of parameters $x_{n}$ and $x_{v}$.

\begin{tabular}{lccccc}
\hline Leq $(A)[\mathrm{dB}]$ & Leq $(A) \geq 85$ & $85>$ Leq $(A) \geq 80$ & $80>$ Leq $(A) \geq 75$ & $75>$ Leq $(A) \geq 70$ & Leq $(A)<70$ \\
\hline$x_{n}$ & 1 & 0.75 & 0.50 & 0.25 & 0 \\
\hline$a_{v}\left[\mathrm{~m} / \mathrm{s}^{2}\right]$ & $a_{v} \geq 0.90$ & $0.90>a_{v} \geq 0.65$ & $0.65>a_{v} \geq 0.35$ & $0.35>a_{v} \geq 0.2$ & $a_{v}<0.2$ \\
\hline$x_{v}$ & 1 & 0.75 & 0.50 & 0.25 & 0 \\
\hline
\end{tabular}

TABLE 5: Determination of comfort index (CI) (rail) and perceived comfort (CP) (rail).

\begin{tabular}{|c|c|c|c|c|c|}
\hline \multirow[b]{2}{*}{ CI (rail) (Comfort Index) } & $1 \geq \mathrm{CI} \geq 0.9$ & $0.9>\mathrm{CI} \geq 0.75$ & $0.75>\mathrm{CI} \geq 0.50$ & $0.50>\mathrm{CI} \geq 0.25$ & $0.25>\mathrm{CI} \geq 0$ \\
\hline & $\begin{array}{c}\text { Extremely } \\
\text { uncomfortable }\end{array}$ & Uncomfortable & $\begin{array}{c}\text { Average } \\
\text { comfortable }\end{array}$ & Comfortable & $\begin{array}{c}\text { Highly } \\
\text { comfortable }\end{array}$ \\
\hline \multirow[b]{2}{*}{ CP (rail) (Comfort Perceived) } & $\mathrm{CP} \leq 2$ & $2>\mathrm{CP} \geq 4$ & $4>\mathrm{CP} \geq 6$ & $6>\mathrm{CP} \geq 8$ & $8>\mathrm{CP} \geq 10$ \\
\hline & $\begin{array}{c}\text { Extremely } \\
\text { uncomfortable }\end{array}$ & Uncomfortable & $\begin{array}{c}\text { Average } \\
\text { comfortable }\end{array}$ & Comfortable & $\begin{array}{c}\text { Highly } \\
\text { comfortable }\end{array}$ \\
\hline
\end{tabular}

The formulation used to define the CI (rail) is the following:

$$
\mathrm{CI}(\text { rail })=x_{n} \cdot \alpha_{n}+x_{v} \cdot \alpha_{v}
$$

where $x_{n}$ is noise coefficient; $x_{v}$ is vibration coefficient; $\alpha_{n}$ is weight assigned to the noise class; $\alpha_{v}$ is weight assigned to the vibration class.

The weights $\alpha_{n}$ and $\alpha_{v}$ were set equal to $\alpha_{n}=0.7$ and $\alpha_{v}=$ 0.3 , according to the sample survey presented in Section 4.

The values $x_{n}$ and $x_{v}$ dependent on noise and vibrations measured on board the vehicle are shown in Table 4 .

For the definition of $x_{n}$ and $x_{v}$, the results obtained from the preliminary survey were considered using a tolerance of $5 \%$; that is, for each value (i.e., $65 \mathrm{~dB}$ or $0.20 \mathrm{~m} / \mathrm{s}^{2}$ ) we considered a single class of $x_{n}$ or $x_{v}$ if the difference, in percentage terms, between the values of " $i$ " and of " $i+1$ " was less than $5 \%$.

Applying formulation (2), the specific Comfort Index for a given route between two stations and for a predetermined time interval can be determined.

Through the thresholds defined in Table 4 it is possible to determine the level of measured CI (rail), shown in Table 5, concerning the considered transport. In Table 5 the thresholds useful to define the CP (rail) identified by interviewees in the survey on transport are also given.

\section{Testing and Validation of the Comfort Index (CI) (Rail)}

To validate the proposed methodology, an experimental campaign on a reference test site was conducted. The test site is identified in the route Cosenza Vaglio Lise-Rogliano, Figure 8 , which is daily traveled by trains of Ferrovie della Calabria; it develops for $25.89 \mathrm{~km}$ and passes through 15 stations crossing Cosenza, Pedace, Aprigliano, Figline, and Rogliano. The test site has 15 tunnels, which are very restrictive in terms of noise on board.

Measurements consisted in

(i) detecting the stations along the route Cosenza Vaglio Lise-Rogliano;

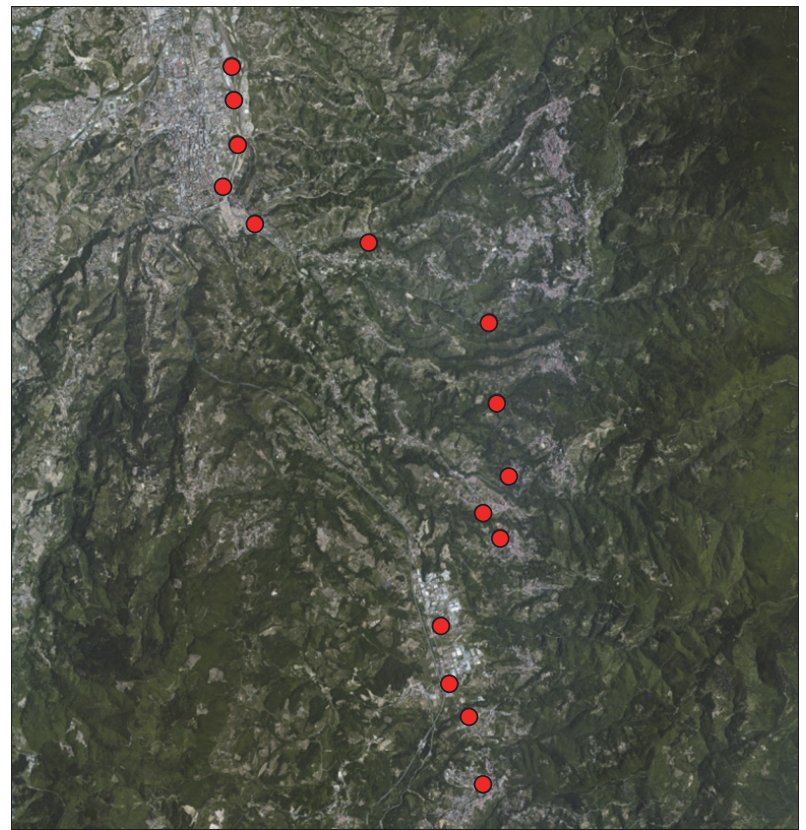

Figure 8: Test site Cosenza Vaglio Lise-Rogliano.

(ii) measuring the noise perceived by users on board the trains using the WED 007;

(iii) measuring the vibrations transmitted to the body through the VIB 008;

(iv) georeferencing the paths by using the smartphone' GPS.

Measurements were carried out on the three trains of Ferrovie della Calabria which daily walk the route Cosenza-Rogliano, in order to get more information and a better validation of the presented model. The trains involved in measurements are described as follows.

\subsection{Train Types}

6.1.1. DE M4c.500 STADLER Railcar. The De M4c.500 is railcar, a two-drawer articulated railcar suitable for traction with 

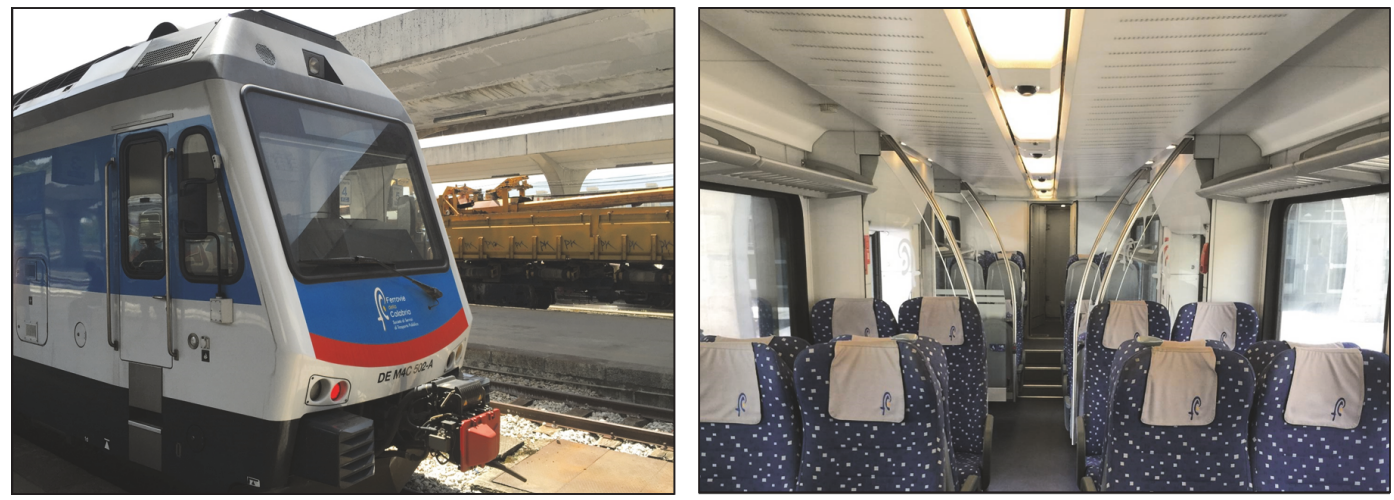

FIGURE 9: DE M4c.500 STADLER Railcar.
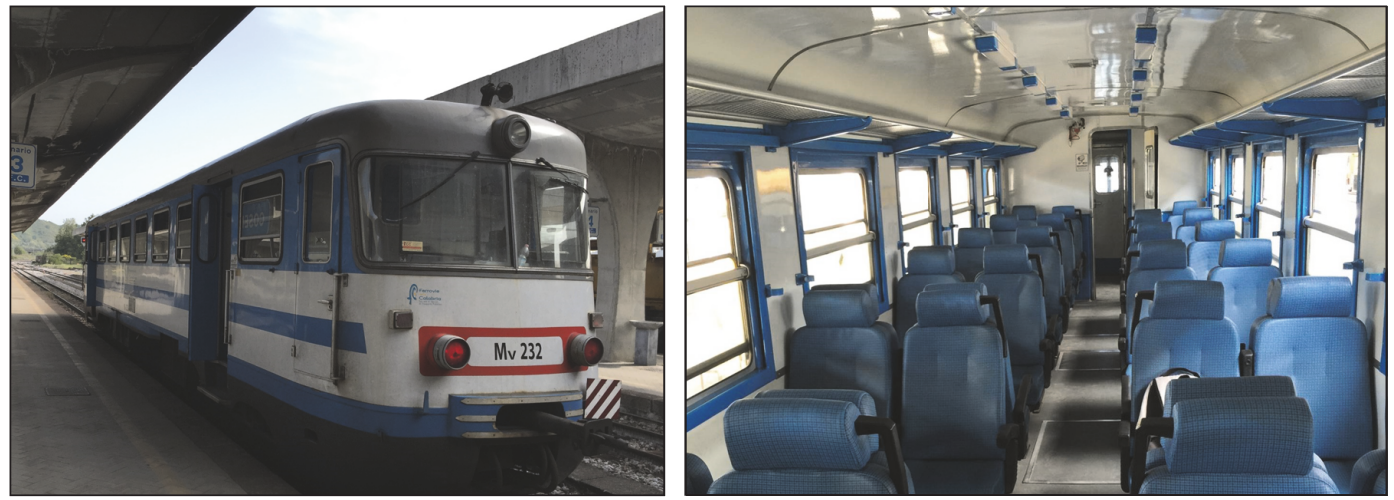

Figure 10: FCL M2.200 BREDA Railcar.
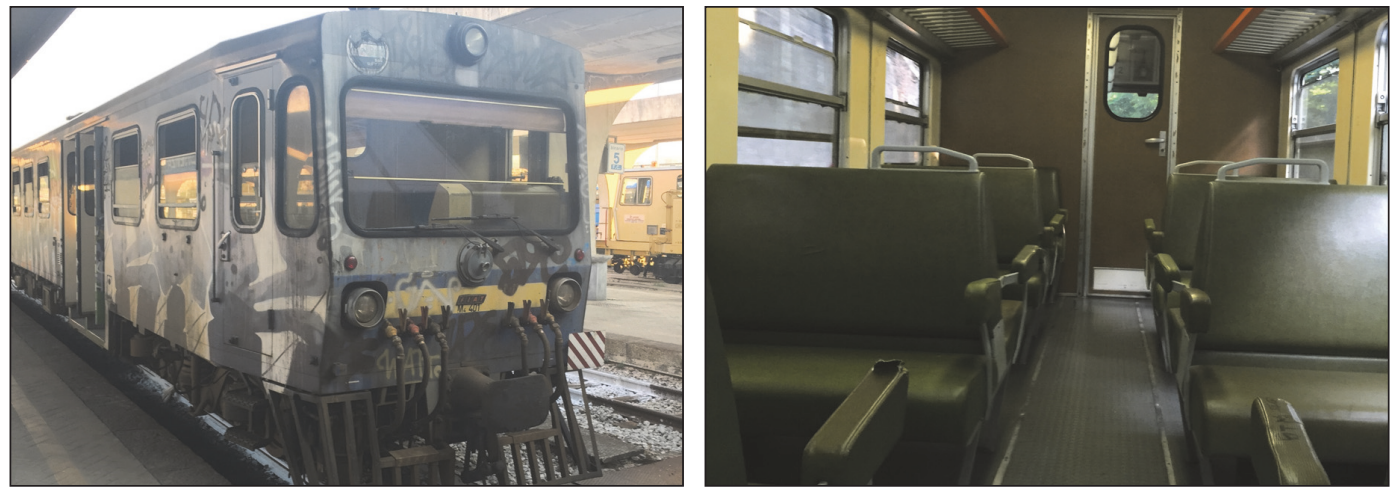

FIGURE 11: M4.400 FIAT Railcar.

rack, manufactured by the Stadler Rail Group Swiss Company for Ferrovie della Calabria. It is the first model (Figure 9), manufactured by Stadler for the Italian market, with narrow gauge $(950 \mathrm{~mm})$ and partially low loader. The system, ordered by Ferrovie della Calabria in 2007, touched rails for the first time at the end of 2009 in Cosenza Vaglio Lise deposit. The system consists of two crates, each one with a Cummins 6 cylinder engine and electric generatrix, connected to two engines axes at the ends of the carriage, all equipped with a toothed wheel. The placement of propulsion equipment above the motor bogies, in the front zones of railcar, ensures a high traction force even on steep slope sections, with an approved maximum speed equal to $80 \mathrm{Km} / \mathrm{h}$. The system provides a total of 100 seats for each railcar.

6.1.2. FCL M2.200 BREDA Railcar. The FCL M2.200 is a railcar produced in the early 70s, from Breda as an evolution of the narrow gauge $(950 \mathrm{~mm}) 120$ series M2 railcar (Figure 10). The system is composed of a single crate with diesel engine produced by Man Voith with retarder, which is a wear-free braking system with a hydromechanical transmission. The approved maximum speed is $90 \mathrm{~km} / \mathrm{h}$. The system provides a total of 52 seats. 


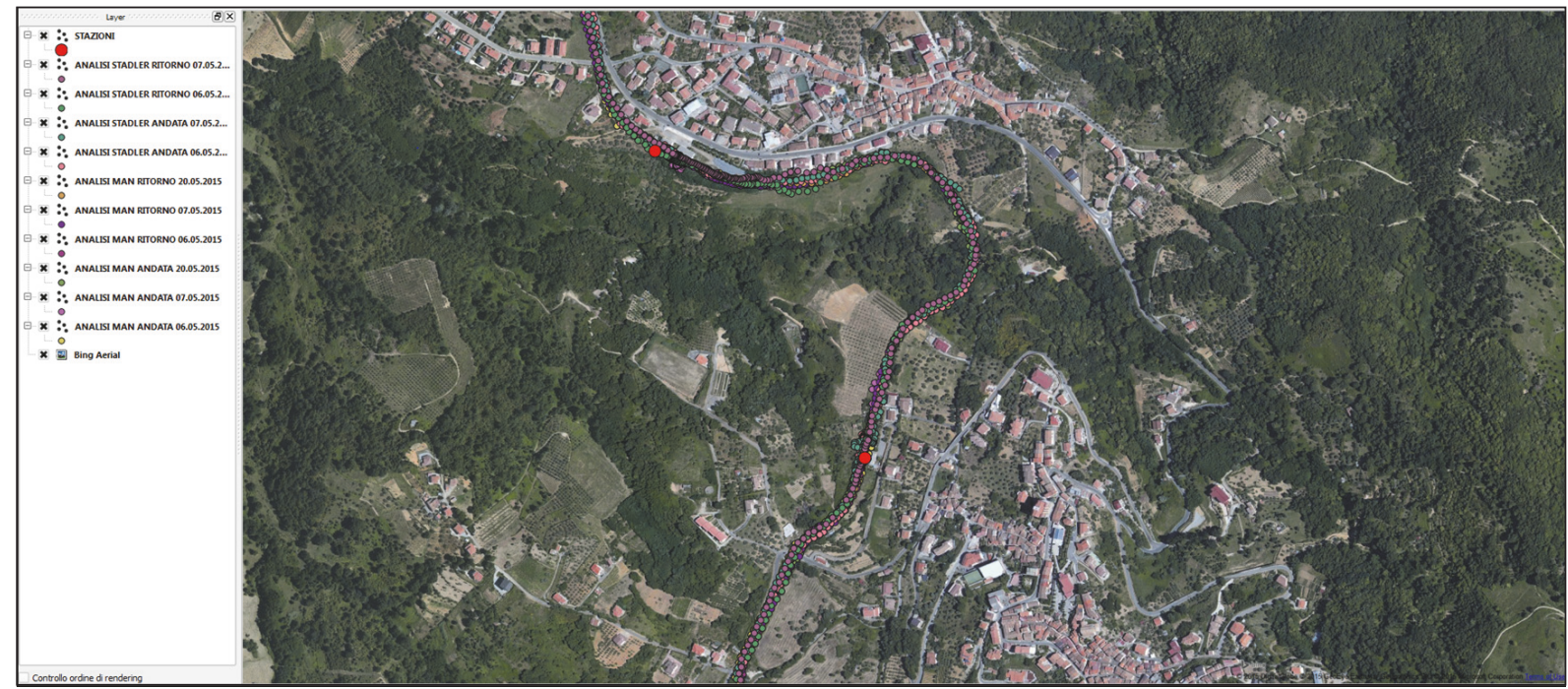

FIGURE 12: Reliefs georeferencing on GIS.

TABLE 6: Calculation of CI (rail) and CP (rail) on the test site Cosenza Vaglio Lise-Rogliano (i_th lap).

\begin{tabular}{|c|c|c|c|c|c|c|}
\hline \multirow{2}{*}{ Rail segment } & \multicolumn{2}{|c|}{ DE M4c.500 Stadler Rail } & \multicolumn{2}{|c|}{ FCL M2.200 BREDA } & \multicolumn{2}{|c|}{ FIAT M4 } \\
\hline & CI (rail) & $\mathrm{CP}$ (rail) & CI (rail) & $\mathrm{CP}$ (rail) & CI (rail) & $\mathrm{CP}$ (rail) \\
\hline Cosenza V.L.-Cosenza Monaco & 0.075 & 9.6 & 0.425 & 7.9 & 0.600 & 5.3 \\
\hline Cosenza Monaco-Cosenza Camp. & 0.175 & 9.2 & 0.425 & 7.3 & 0.700 & 4.9 \\
\hline Cosenza Campanella-Cosenza C. & 0.175 & 9.3 & 0.425 & 7.4 & 0.600 & 5.7 \\
\hline Cosenza Centro-Casali & 0.425 & 7.5 & 0.600 & 4.4 & 0.775 & 3.9 \\
\hline Casali-Bosco & 0.425 & 6.1 & 0.600 & 4.1 & 0.600 & 5.9 \\
\hline Bosco-Pedace & 0.425 & 6.2 & 0.775 & 2.2 & 0.600 & 4.3 \\
\hline Pedace-Pietrafitta & 0.425 & 6.1 & 0.850 & 1.9 & 0.775 & 1.9 \\
\hline Pietrafitta-Aprigliano & 0.425 & 6.7 & 0.600 & 4.2 & 0.600 & 4.1 \\
\hline Aprigliano-Piane Crati & 0.250 & 7.7 & 0.600 & 5.3 & 0.600 & 4.9 \\
\hline Piane Crati-Figline/Cellara & 0.250 & 7.9 & 0.600 & 5.6 & 0.600 & 5.6 \\
\hline Figline/Cellara-Mangone & 0.250 & 7.7 & 0.675 & 5.4 & 0.600 & 5.3 \\
\hline Mangone-Piano Lago & 0.425 & 6.6 & 0.425 & 6.2 & 0.600 & 5.9 \\
\hline Piano Lago-S. Stefano & 0.425 & 7.0 & 0.600 & 6.3 & 0.600 & 6.0 \\
\hline S. Stefano-Rogliano & 0.425 & 6.7 & 0.600 & 5.9 & 0.600 & 5.7 \\
\hline
\end{tabular}

6.1.3. M4.400 FIAT Railcar. The M4.400 is a railcar produced by Ferrosud in the mideighties, as the natural evolution of M2.200 railcar (Figure 11). The system is composed of a single crate, with two Iveco Diesel 6-cylinder engines, positioned between the pivots of wheels and connected to two carriages. It has mechanical transmission with a 5-speed gearbox and hydraulic coupling. The approved maximum speed is $100 \mathrm{Km} / \mathrm{h}$. The system provides a total of 52 seats and two folding seats.

6.2. Validation of the Comfort Index (CI) (Rail). For each of the three transport systems described, 15 outward measurements and 15 return measurements were carried out, for a total of 90 measurements. Every measurement was georeferenced and exported to GIS, Figure 12, for processing data, even graphical, using the Open Source Quantum GIS software.
Following experimentations, all the measurements were processed and the value of CI (rail) for each of the three trains was calculated.

Starting from sound level meter and accelerometer measurements carried on board the trains, the CI (rail) was calculated according to the scheme described in the previous paragraph. The calculation of this indicator has provided guidance on the level of general comfort determined by measurements taken on board.

Once the CI (rail) for each route is determined, it was possible to georeference the comfort trend on the whole test site for each of the three trains, as shown in Figure 13.

In Table 6, the value of CI (rail) and relative CP (rail) is shown for each of the routes and for each of the transport systems.

The comparison between the CI (rail), determined by the formulation (1), and the CP (rail), calculated by the average 


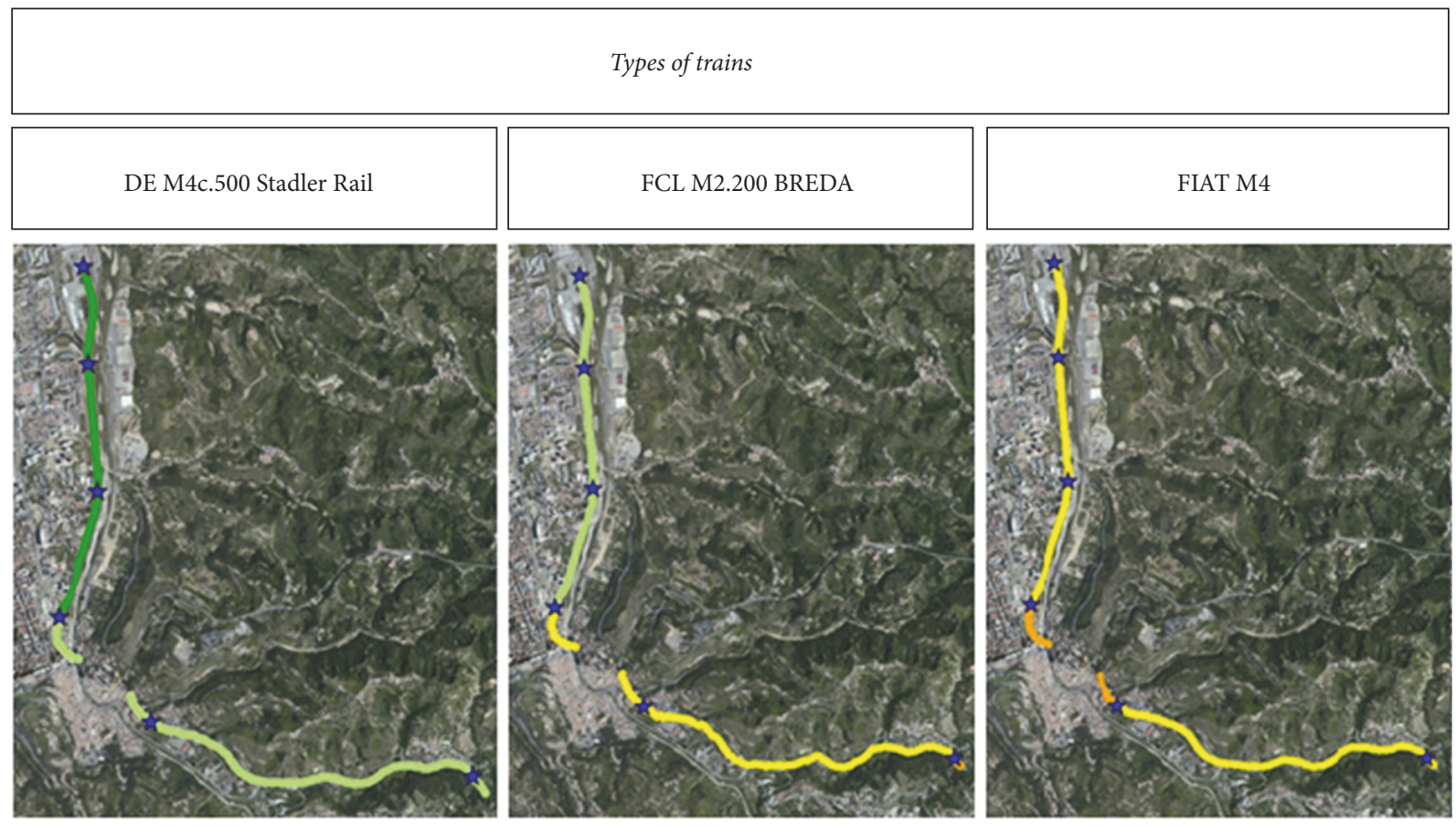

Figure 13: Excerpt of the CI (rail) trend on the route Cosenza Vaglio Lise-Bosco.

TABLE 7: Chi-square test.

\begin{tabular}{lc}
\hline & Chi-sq (4,0.95) \\
\hline DE M4c.500 Stadler Rail & 2.04 \\
FCL M2.200 BREDA & 3.71 \\
FIAT M4 & 3.53 \\
\hline
\end{tabular}

of scores given by users in the survey forms and shown in Table 6, highlights a good correspondence between the values of CI (rail) and CP (rail).

Differences are marked in specific routes and influenced by the presence of tunnels. As can be seen in Table 6, the Stadler DE M4c.500 appears to be the most comfortable train, with a relatively high comfort. Being the noise most onerous in terms of comfort compared to vibration, as defined by the interviewees, trains that allow the opening of windows (Breda and FIAT) result to be extremely uncomfortable.

The correspondence between CI and CP is shown in Figures 14, 15, and 16 and in addition, a chi-square test was applied to determine if there are no significant differences.

Variations between CI and CP may be due to kinematic factors and punctual changes in the infrastructure (i.e., tunnel, etc.). However, $\mathrm{CP}$ value may vary slightly compared to $\mathrm{CI}$, since the interviewee could differently evaluate the actual situation of comfort within the trains.

As shown in Table 7, there are no significant differences between $\mathrm{CI}$ and $\mathrm{CP}$ in any of the three types of trains.

\section{Conclusions}

This research has previously dealt with a preliminary sample survey, administered to regular users of the transport service,

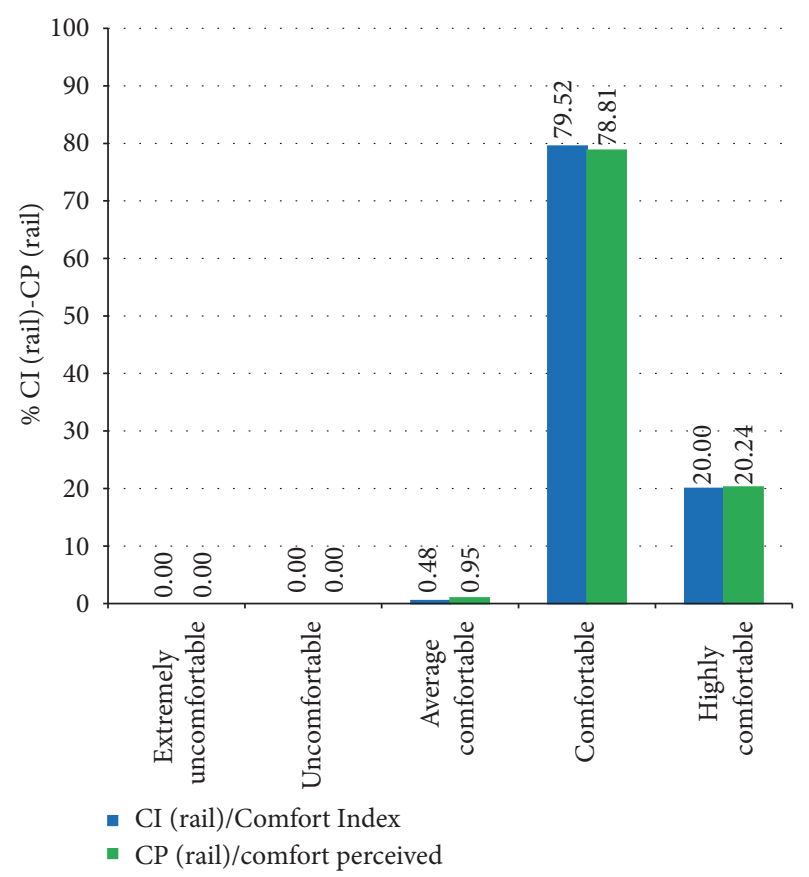

Figure 14: Comparison CI and CP-DE M4c.500 Stadler Rail.

with the aim of identifying the perceived noise level and determining the perceived noise thresholds. Subsequently, a sample survey on board the vehicle, administered to the transport service users, has allowed identifying which perceived environmental factors, between noise and vibration, significantly affect the perceived comfort. 


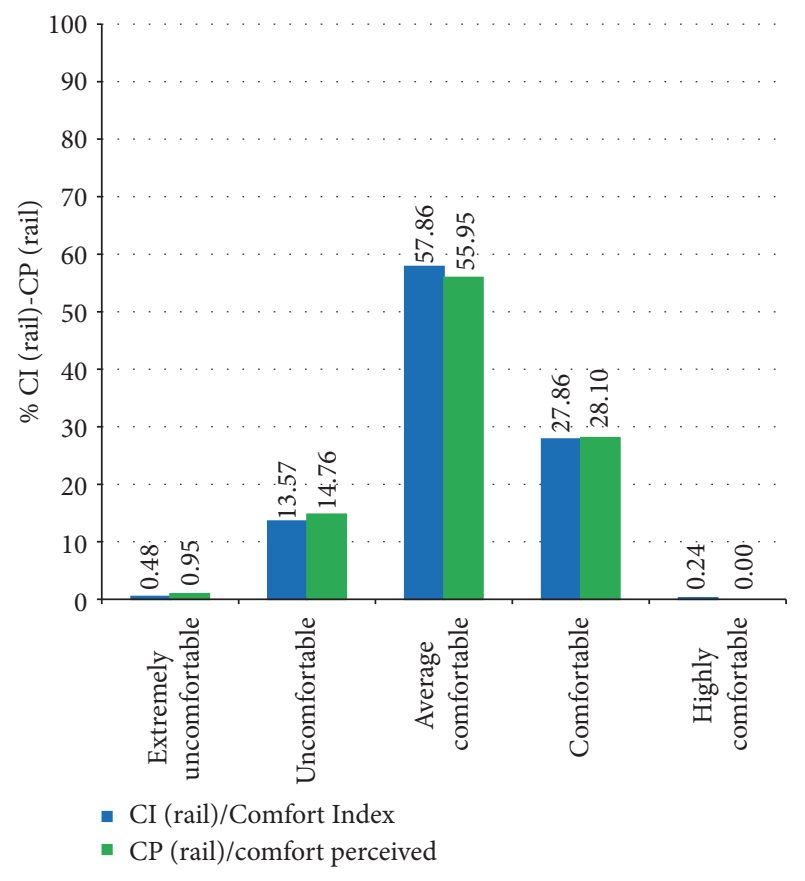

Figure 15: Comparison CI and CP-FCL M2.200 BREDA.

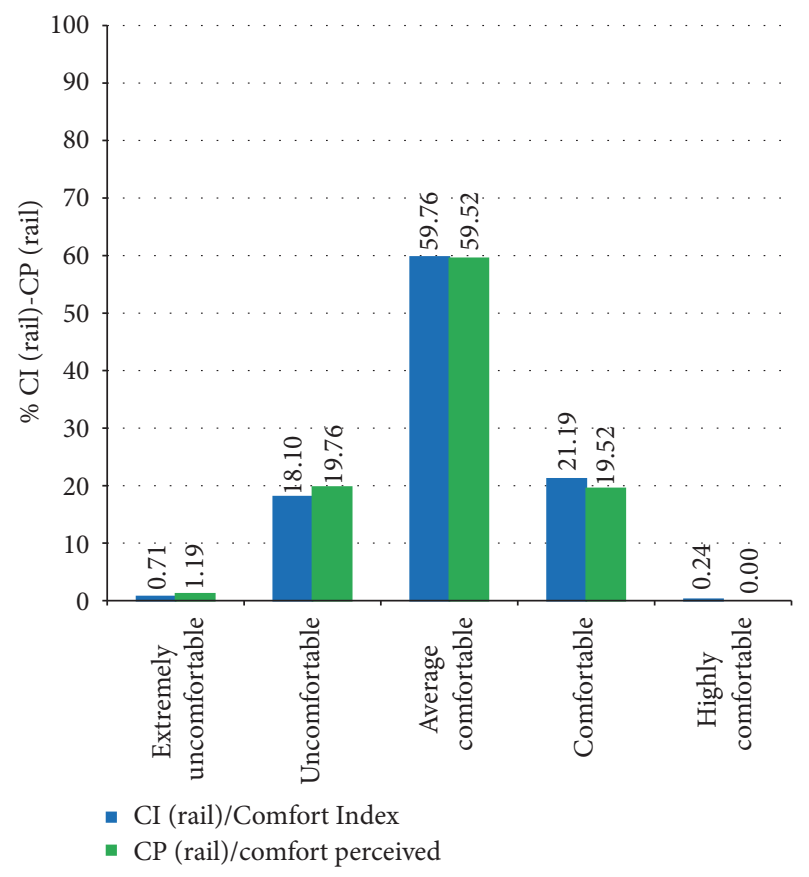

Figure 16: Comparison CI and CP-FIAT M4.

A specific CI (rail) for rail transport was defined and calibrated, depending on noise and vibration measured during the trip. Finally, this CI (rail) was validated with measurements on three types of trains running on the route Cosenza-Rogliano.

Therefore, through objective measurements of noise and vibration, this study allowed determining a typical comfort environmental indicator CI (rail), representative of the userperceived service quality.

\section{Conflicts of Interest}

The authors declare that they have no conflicts of interest.

\section{Acknowledgments}

Thanks are due to AESSE Environment s.r.l. and $01 \mathrm{~dB}$ Acoem and I.E.S. Integrated Engineering Services Srl for providing instruments used in this research and Eng. Piertoni Cambiaggio for the fruitful cooperation offered in training authors to use instrumentation.

\section{References}

[1] Commissione Europea, Una strategia per una crescita intelligente, sostenibile e inclusiva, Europa 2020, Bruxelles, 2010.

[2] UNI EN 13816:2002, “Trasporti, Logistica e Servizi-Trasporto pubblico di passeggeri-Definizione, obiettivi e misurazione della qualità del servizio".

[3] C. Y. Lin, L. J. Chen, Y. Y. Chen, and W. C. Lee, A comfort measuring system for public transportation systems using participatory phone sensing, ACM PhoneSense, 2010.

[4] S. S. Andaleeb, M. Haq, and R. I. Ahmed, "Reforming innercity bus transportation in a developing country: A passenger-driven model," Journal of Public Transportation, vol. 10, no. 1, p. 1, 2007.

[5] M. Cantwell, B. Caulfield, and M. OMahony, "Examining the factors that impact public transport commuting satisfaction," Journal of Public Transportation, vol. 12, no. 2, p. 1, 2009.

[6] I. D. Griffiths and F. J. Langdon, "Subjective response to road traffic noise," Journal of Sound and Vibration, vol. 8, no. 1, pp. $16-32,1968$.

[7] R. Gambart, H. Myncke, and A. Cops, "Study of annoyance by traffic noise in Leuven (Belgium)," Applied Acoustics, vol. 9, no. 3, pp. 193-203, 1976.

[8] D. Ouis, "Annoyance from road traffic noise: a review," Journal of Environmental Psychology, vol. 21, no. 1, pp. 101-120, 2001.

[9] D. Ouis, "Annoyance caused by exposure to road traffic noise: an update," Noise and Health, vol. 4, no. 15, pp. 69-72, 2002.

[10] V. Barone, F. Crocco, and D. Mongelli, "A mathematical model for traffic noise prediction in an urban area," in Proceedings of the 4th WSEAS International Conferense on Urban Planning and Transportation UPT, 2011, Corfu Island, pp. 405-410, Greece, 2011.

[11] B. Vincenzo, F. Crocco, and D. W. E. Mongelli, "An integrated prediction model to define the level of noise in urban areas," in Proceedings of the 4th WSEAS International Conferense on Urban Planning and Transportation UPT, 2011, Corfu Island, pp. 399-404, Greece, 2011.

[12] D. W. E. Mongelli, "An integrated prediction model for traffic noise in an urban area," in Proceedings of the IEEE International Conference on Service Operations and Logistics, and Informatics (SOLI '13), pp. 198-204, Dongguan, China, July 2013.

[13] B. De Coensel, K. Sun, W. Wei et al., "Dynamic noise mapping based on fixed and mobile sound measurements," in Proceedings of the 10th European Congress and Exposition on Noise Control Engineering (Euronoise 2015), pp. 2339-2344, 2015. 
[14] C. Guarnaccia, "Advanced tools for traffic noise modelling and prediction," WSEAS Transactions on Systems, vol. 12, no. 2, pp. 121-130, 2013.

[15] G. Iannone, C. Guarnaccia, and J. Quartieri, "Speed distribution influence in road traffic noise prediction," Environmental Engineering and Management Journal, vol. 12, no. 3, pp. 493-501, 2013.

[16] S. Sanok, F. Mendolia, M. Wittkowski, D. Rooney, M. Putzke, and D. Aeschbach, "Passenger comfort on high-speed trains: effect of tunnel noise on the subjective assessment of pressure variations," Ergonomics, vol. 58, no. 6, pp. 1022-1031, 2015.

[17] P. Mohan, V. Padmanabhan, and R. Ramjee, "Nericell: rich monitoring of road and traffic conditions using mobile smartphones," in Proceedings of the 6th ACM Conference on Embedded Network Sensor Systems (SenSys '08), pp. 323-336, Raleigh, NC, USA, November 2008.

[18] E. Miluzzo, N. D. Lane, K. Fodor et al., "Sensing meets mobile social netwo rks: the design, implementation and evaluati on of the cenceme application," in Proceedings of the 6th ACM Conference on Embedded Networked Sensor Systems (SenSys '08), pp. 337-350, ACM, New York, NY, USA, November 2008.

[19] H. Lu, W. Pan, N. D. Lane, T. Choudhury, and A. T. Campbell, "SoundSense: scalable sound sensing for people-centric applications on mobile phones," in Proceedings of the 7th ACM International Conference on Mobile Systems, Applications, and Services (MobiSys '09), pp. 165-178, Krakov, Poland, June 2009.

[20] D. C. Festa, D. W. E. Mongelli, V. Astarita, and P. Giorgi, "First results of a new methodology for the identification of road surface anomalies," in Proceedings of the IEEE International Conference on Service Operations and Logistics, and Informatics (SOLI '13), pp. 192-197, Dongguan, China, July 2013.

[21] V. Astarita, D. C. Festa, D. W. E. Mongelli, and A. Tassitani, "New methodology for the identification of road surface anomalies," in Proceedings of the IEEE International Conference on Service Operations and Logistics, and Informatics (SOLI '14), pp. 149-154, IEEE, Qingdao, China, October 2014.

[22] V. Barone, D. W. E. Mongelli, and A. Tassitani, "Definition and validation of a methodology to identify the road surface anomalies on the streets by measuring the noise and vibration," International Journal of Mathematical Models and Methods in Applied Sciences, vol. 9, pp. 677-682, 2015.

[23] Directive 2002/44/EC, "on the minimum health and safety requirements regarding the exposure of workers to the risks arising from physical agents (vibration) (sixteenth individual Directive within the meaning of Article 16(1) of Directive 89/391/EEC)," The European Parliament And of The Council, 2002.

[24] D. Lgs, "81/2008 Testo unico in materia di sicurezza sul lavoro".

[25] ISO 5349-1:2001, "Mechanical vibration-Measurement and evaluation of human exposure to hand-transmitted vibrationPart 1: General requirements".

[26] ISO 2631-1:1997, "Mechanical vibration and shock-Evaluation of human exposure to whole-body vibration-Part 1: General requirements".

[27] NF S 31-084:2002, "Mèthode de measurage des niveaux d'exposition au bruit en milieu de travail".

[28] ISO 9612:1997, "Guidelines for the measurement and assessment of exposure to noise in a working environment".

[29] V. Barone, D. W. E. Mongelli, and A. Tassitani, "Vibrational comfort on board the vehicle: Influence of speed bumps and comparison between different categories of vehicle," Advances in Acoustics and Vibration, vol. 2016, Article ID 2676021, 2016. 


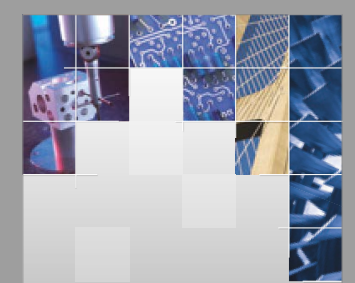

\section{Enfincering}
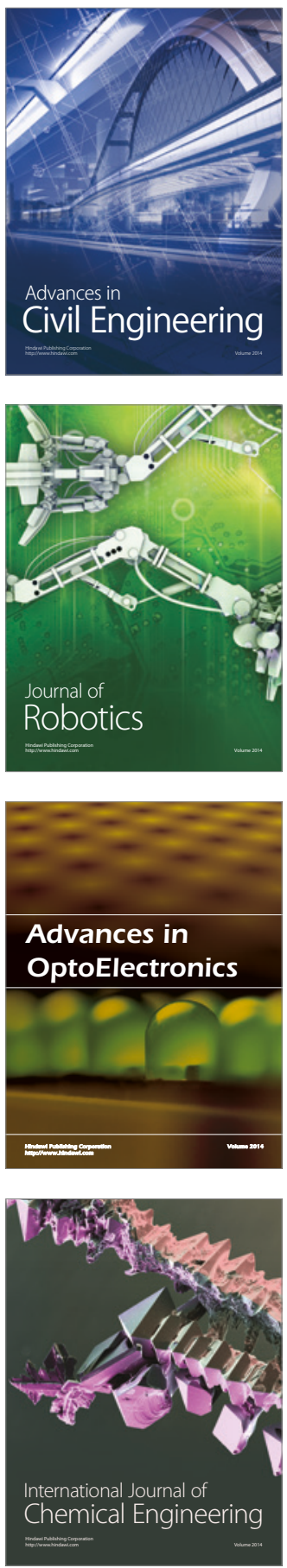

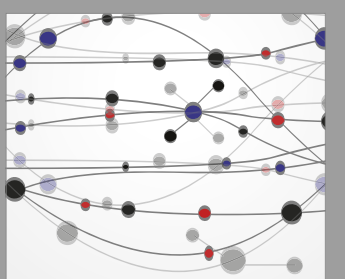

The Scientific World Journal

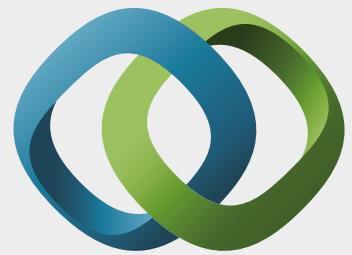

\section{Hindawi}

Submit your manuscripts at

https://www.hindawi.com
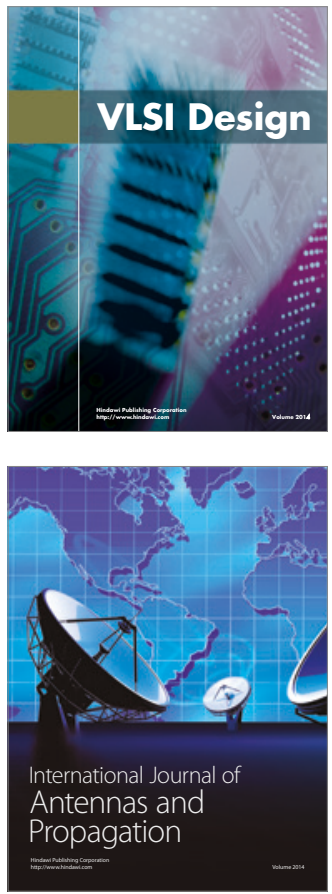

\section{Rotating}

Machinery
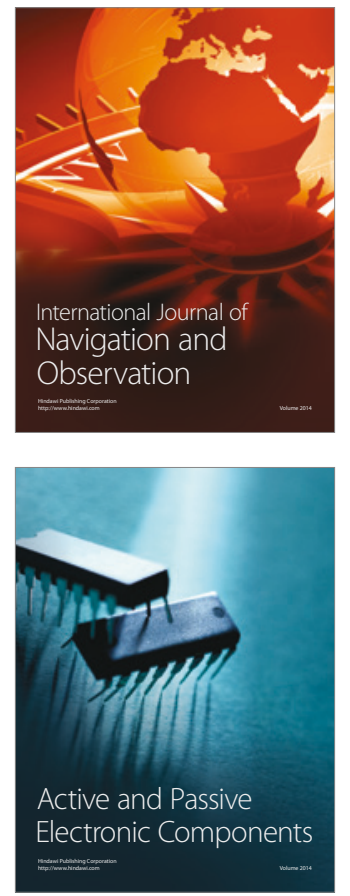
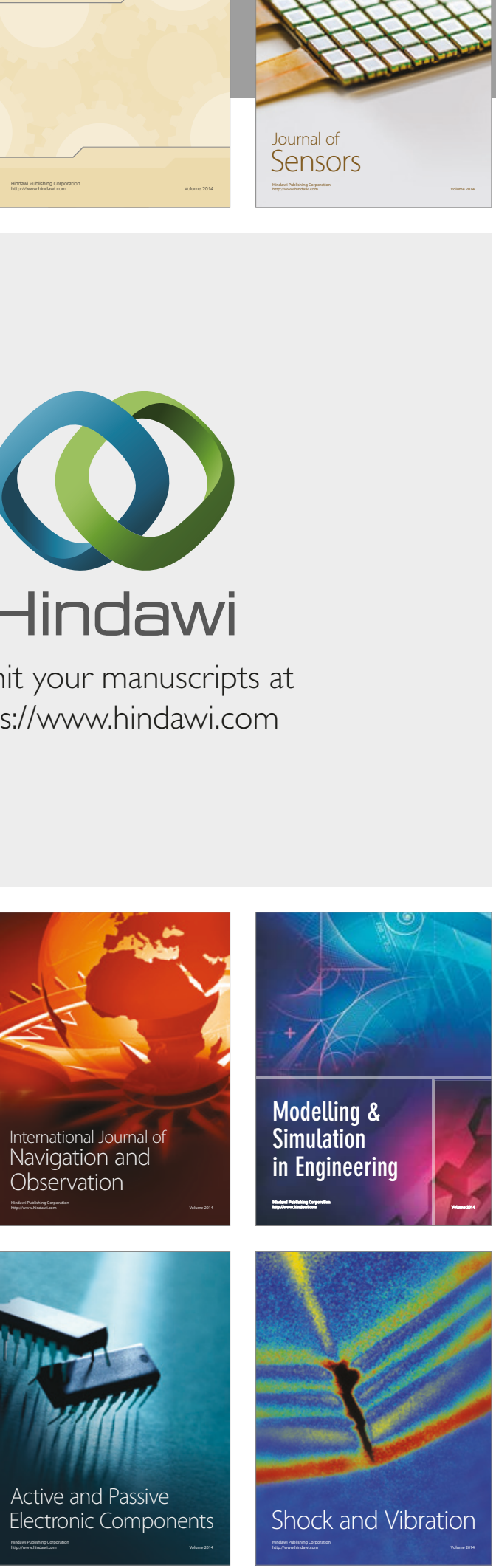
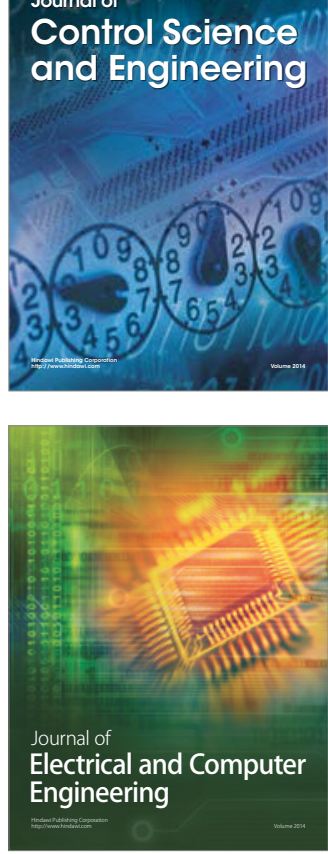

Distributed

Journal of

Control Science

and Engineering
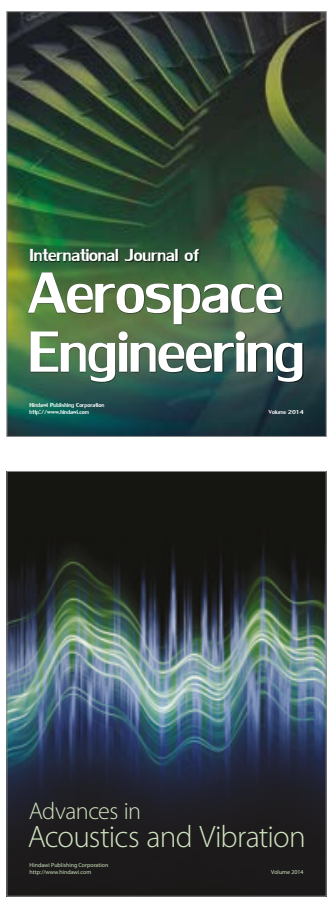

Sensor Networks 